\title{
Un diagnostic prénatal ultra-précoce chez la souris
}

\section{Les nouvelles \\ de ce numéro}

ont été préparées par : Jean-Claude Dreyfus

\section{Serge Erlinger}

Jean-Pierre Grünfeld

Axel Kahn

Marc Peschanski
1. McLaren A. Prenatal diagnosis before implantation : opportunities and problems. Prenat Diagn 1985 ; 5 : 85-90.

2. Monk M, Handyside A, Hardy K, Wittingham D. Preimplantation diagnosis of deficiency of HPRT in a mouse model for LeschNyhan syndrome. Lancet 1987 ; ii : 423-5.
Le diagnostic prénatal des maladies génétiques a fait récemment des progrès considérables; de la ponction amniotique du deuxième trimestre on est passé aux villosités choriales prélevées au premier trimestre $\left(\mathrm{m} / \mathrm{s} n^{\circ} 1\right.$, vol. 1 , p. 52). Le prochain objectif, au moins dans certains cas, pourrait être l'œuf avant même son implantation utérine. Sa réalisation se heurte à des obstacles considérables, aussi bien techniques qu'éthiques [1]. Un premier succès expérimental vient d'être obtenu en Angleterre.

Marilyn Monk et al. [2] ont choisi le déficit en hypoxanthine-guanine phosphoribosyltransférase (HPRT), lié au sexe, qui chez l'homme est cause du redoutable syndrome de Lesch-Nyhan. Ces auteurs ont croisé des femelles rendues hétérozygotes pour ce déficit avec des mâles normaux. Au troisième jour de la gestation les embryons, au stade huit cellules, sont prélevés et mis en culture pour 24 heures. Un des huit blastomères est utilisé pour le microdosage enzymatique de l'HPRT ainsi que d'une enzyme voisine mais dont le gène est codé par un autosome, l'APRT ( $\mathrm{A}=$ adénine $)$. Les autres blastomères sont implantés chez des femelles réceptrices, au troisième jour d'une pseudogestation induite par la gonadotrophine.

Le rapport HPRT/APRT divise les embryons en deux groupes, selon qu'il est au voisinage de 0,1 ou de 1 . Le taux de HPRT n'est en effet pas nul chez les animaux déficients, ce qui pourrait peut-être s'expliquer par la persistance, au stade huit cellules, d'une faible activité résiduelle de l'ARN messager maternel. Les embryons réimplantés sont testés après 14 jours pour leur activité HPRT ; les résultats confirment les prévisions faites à partir du blastomère.

Il apparaît donc possible de faire un diagnostic prénatal de déficit en HPRT sur une seule cellule de souris au stade de pré-implantation sans compromettre la viabilité de l'embryon. Peut-on déjà songer à une éventuelle application à l'espèce humaine ? On pourrait en principe obtenir des embryons au stade de pré-implantation soit par lavage utérin, soit après fécondation in vitro. On ne peut le faire que si des méthodes ultrasensibles et de réponse rapide sont disponibles, ce qui exclut actuellement les sondes à ADN. Pour des raisons techniques, et du fait de sa haute gravité, le syndrome de Lesch-Nyhan sera vraisemblablement le premier candidat à un tel diagnostic. Des essais préliminaires sont en cours [2] pour préciser le profil de l'expression de l'HPRT aux premiers stades de développement de l'embryon humain. 